\title{
The Contribution of Commercial Banks to GDP Growth in Nigeria using Autoregressive Distributed Lag Model
}

\author{
Monday Osagie ${ }^{* 1}$ Adenomon; Godson Obinna ${ }^{1}$ Ogujiofor \& Clara Adebukola ${ }^{2}$ Adenomon \\ 1. Department of Statistics, Nasarawa State University, Keffi. \\ 2. Department of Administration, Federal Medical centre, Bida \\ *Corresponding author: adenomonmo@nsuk.edu.ng +2347036990145 \\ ogbuai@yahoo.com; bukkynet_82@yahoo.com
}

\begin{abstract}
In most econometrics literature, the Autoregressive Distributed Lag (ARDL) model is often applied in many economic analyses to study short and long run relationships. This is because ARDL model can deal with economic variables that are integrated of different order $(\mathrm{I}(0), \mathrm{I}(1)$ or combination of both) and also it is robust where there is single long-run relationship between the underlying variables in a simple sample size. This study applied the ARDL model to examine the contributions of commercial Banks to GDP growth in Nigeria. To achieve this, annual data covering 1981 to 2015 for loans and advances, savings, lending rates and GDP of Financial Institutions were collected from CBN bulletin. The ADF test revealed that the variables are I(1) except for lending rate which was of $\mathrm{I}(0)$ order. The $\operatorname{ARDL}(1,1,1,2)$ model revealed that loans and advances, and lending rates are significantly positively related to GDP in Nigeria but savings was not significant in the model. The model revealed some evidence of short run relationships while the ecm $(-1)$ was -0.6156 (P-value $=0.0038<0.05)$ which means that the rate of the speed of adjustment to equilibrium is $61.56 \%$ annually. The estimated model is free from serial correlation, multicollinearity, heteroscedasticity while the model is stable and the residuals are normally distributed. The study recommends that savings and savings culture should be encouraged in Nigeria since economic theory states that savings and investment are related in any economic development.
\end{abstract}

Keywords: Gross Domestic Product (GDP), Lending Rates, Savings, Loans and Advances, ARDL

\subsection{Introduction}

Pesaran, et al. (2001) proposed an Autoregressive Distributed Lag (ARDL) or Bounds testing approach to investigate the existence of cointegration relationship among variables. There are three specific advantages associated with this approach (Udoh et al. 2015): 
- It circumvents the problem of the order of integration associated with the Johansen likelihood approach.

- Unlike most of the conventional multivariate cointegration procedures which are valid for large sample size, the bounds test approach is suitable for sample size study.

- It provides unbiased estimates of the long run model and valid t-statistics even when some of the regressors are endogenous.

Autoregressive Distributed Lag (ARDL) Models have played a prominent role in numerous application in the Nigerian economy. Examples include the study of fiscal decentralization, economic growth and human resources development in Nigeria (Udoh, et al. 2015); Doguwa and Alade (2015) compared ARDL model among other models on the modeling of Nigeria's external reserves; Udom and Yaaba (2015) used ARDL model on the determination of the monetary policy instrument for Nigeria, and, Musa and Gulumbe (2014) studied the interrelationship between inflation rate and government revenues in Nigeria using ARDL model.

This study applied the ARDL model to examine the contributions of commercial Banks to GDP growth in Nigeria.

\subsection{Empirical Review on the Contribution of Banking Sector to GDP Growth}

According to Adekunle, Salami and Adedipe (2013) a well-developed financial system play several roles to boost efficiency of intermediation through reduction of information, transaction and monitoring costs. It will also enhance investment by identifying and funding good business opportunities, mobilizes savings, encourage trading, hedging and diversification of risk as well as facilitating exchange of goods and services. However, not all savings are used to finance investments despite high demand for credit because of the limited accessibility to credits in Nigeria (Azege, 2007). Indeed, the lack of credit has been cited by firm managers in the developing countries especially Nigeria as their major constraint (Bigstein and Soderbom, 2005). Lack of funds has made it difficult for industries to invest in modern machines, information technology and human resources development which are critical in reducing production costs, raising productivity and improving competitiveness. Also, low investments have been traced to unwillingness of banks to provide credits to manufacturers, owing partly to the mismatch between the short-term nature of banks' funds and the medium to long term nature of funds needed by industries. 
Hashim (2012) posits that despite series of bank reformed aimed at strengthening the ability of banks to efficient services delivery and branch networking as well as funding the real sector to boost Nigerian economy, the dynamic challenges still lingers on the efforts. The problems such as inefficient allocation of funds to the real sector, lack of long-dated funding, decline in domestic credit by the banking sector to the private sector, mismatch of liquidity in the Nigeria economy, etcetera were attributed to the financial inefficiency in the economy.

Abubakar and Gani (2013) investigate the long run relationship between financial development indicators and economic growth in Nigeria for the period 1970-2010. The study used Johansen and Juselius (1990) approach to co integration and Vector Error Correction Modelling (VECM). It was discovered that long-run, liquid liabilities of commercial banks and trade openness exert significant positive influence on economic growth, conversely, credit to the private sector, interest rate spread and government expenditure exert significant negative influence. This implied that, credit to the private sector is marred by the identified problems and government borrowing and high interest rate are crowding out investment and growth. The study recommends that financial reforms in Nigeria should focus more on deepening the sector in terms of financial instruments so that firms can have alternatives to banks' credit which proved to be inefficient and detrimental to growth, moreover, government should inculcate fiscal discipline so as to reduce excessive borrowing from the financial sector and thereby crowding out private investment.

In the same vein, Bhusal (2012) examine the impact of policy reforms on financial development and economic growth in Nepal by employing the annual data spanning from 1965 to 2009. He employed Augmented Dickey Fuller test and exogenous break test as instrument of analysis. The findings revealed that all variables except domestic credit are nonstationary at the level, when time series properties of variables help to detect the impact of policy reforms are examined with a structural break; only economic growth experienced a shock, growing positively after the liberalization. Similarly, domestic credit provided by banks witness negative growth, and it decreased in pace after policy reforms, which implies that the role of government declined after the liberalization.

According to Pearce (1992), credits refer to the process of lending and borrowing of fund from financial able bodies such as banks, government, individuals and other financial 
institutions. It can also be describe as a means of obtaining resources at a certain period of time with an obligation to repay in accordance with the terms and conditions of the credit obtained. Succinctly, credit refers to availability of resources (money) to household, firms and government with an agreement to repay at a stipulated period of time. Pandey, (2006) posits that the credit term to be granted to any customer depends on the norms and practice of the industry.

\subsection{Model Specification}

The ARDL model specification of the functional relationship between the GDP for Financial Institutions and Lending Rates, Loans and Advances and Weighted Average Savings is given below

$$
\begin{aligned}
& \Delta L N G D P F=\alpha_{0}+\beta_{1} L N G D P F_{t-1}+\beta_{2} L N L A_{t-1}+\beta_{3} L N S A V_{t-1}+\beta_{4} L N I N T_{t-1}+ \\
& \sum_{i=1}^{p} \delta_{1 i} \Delta L N G D P F_{t-i}+\sum_{i=0}^{q} \delta_{2 i} \Delta L N L A_{t-i}+\sum_{i=0}^{r} \delta_{3 i} \Delta L N S A V_{t-i}+\sum_{i=0}^{s} \delta_{4 i} \Delta L N I N T_{t-i}+\varepsilon_{t}
\end{aligned}
$$

Where: LNGDDF- Natural Logarithm transform of GDP of Financial Institutions, LNINTNatural Logarithm transform of Lending Rates, LNLA- Natural Logarithm transform of Loans and Advances, LNSAV-Weighted Average Savings, p, q, r, s= Lag lengths for the ARDL model, $\Delta=$ First differencing operator; $\varepsilon=$ white noise disturbance error term, $\alpha_{0}=$ constant in the model, $\beta_{1} \ldots \beta_{k}$ are the long run coefficients, $\delta_{1} \ldots \delta_{k}$ are the short run coefficients.

The bound test approach for the long-run relationship between the macro variables is based on the Wald test (F statistic), by imposing restrictions on the long-run estimated coefficients of one period lagged level of the dependent variable and the independent variables to be equal to zero, that is, $H_{0}: \beta_{1}=\ldots \beta_{k}=0$. Then the calculated $\mathrm{F}$ statistic is compared to the tabulated critical value in Pesaran et al. (2001).The explanatory variables are assumed to be integrated of order zero, or I $(0)$ for values of the lower bound, while the upper bound values assumed that they are integrated of order one, or I(1). Therefore, the decision rule is that if computed F-statistic falls below the lower bound value, I(0), the null hypothesis (no cointegration) cannot be rejected. While if the computed F-statistic exceeds the upper bound value, I(1) then it can be concluded the variables are co-integrated. 
The long-run and short run parameters of equation (1) can then be estimated once a cointegration relationship had been established. The co-integration long run relationship was estimated using the following specification:

$$
L N G D P F=\alpha_{0}+\beta_{1} L N G D P F_{t-1}+\beta_{2} L N L A_{t-1}+\beta_{3} L N S A V_{t-1}+\beta_{4} L N I N T_{t-1}+\varepsilon_{t}
$$

However, to restore equilibrium immediately may not be possible because of the speed of adjustment. This could be caused by the lags and adjustment process used to capture changes in any of the factors affecting GDP overtime. Hence, the error correction model was used to capture the speed of adjustment of GDP model. The model is expressed below thus:

$\Delta L N G D P F=\alpha_{0}+\sum_{i=1}^{p} \delta_{1 i} \Delta L N G D P F_{t-i}+\sum_{i=0}^{q} \delta_{2 i} \Delta L N L A_{t-i}+\sum_{i=0}^{r} \delta_{3 i} \Delta L N S A V_{t-i}+\sum_{i=0}^{s} \delta_{4 i} \Delta L N I N T_{t-i}+\delta_{5} e c t_{t-1}+\varepsilon_{t}$

Where: $e c t_{t-1}=$ the error correction term lagged for one period; $\delta_{5}=$ the coefficient for measuring speed of adjustment in equation (3).

\subsection{Materials and Methods}

Secondary data was employed in this study collected from Central Bank Statistical Bulletin. Annual data was collected on Loan and advances, Lending Rate, Savings and GDP of financial institutions. The data covers a period from 1981 to 2015. The data was transformed using Natural logarithm as Natural Logarithm transform of GDP of Financial Institutions (LNGDDF), Natural Logarithm transform of Lending Rates (LNINT), Natural Logarithm transform of Loans and Advances (LNLA), Natural Logarithm transform of Weighted Average Savings (LNSAV). The Natural Logarithm transform of GDP of Financial Institutions (LNGDDF) was used as the dependent variable.

\subsection{Results and Discussion}

The analysis are carried out using EViews 7.2 Statistical Software 


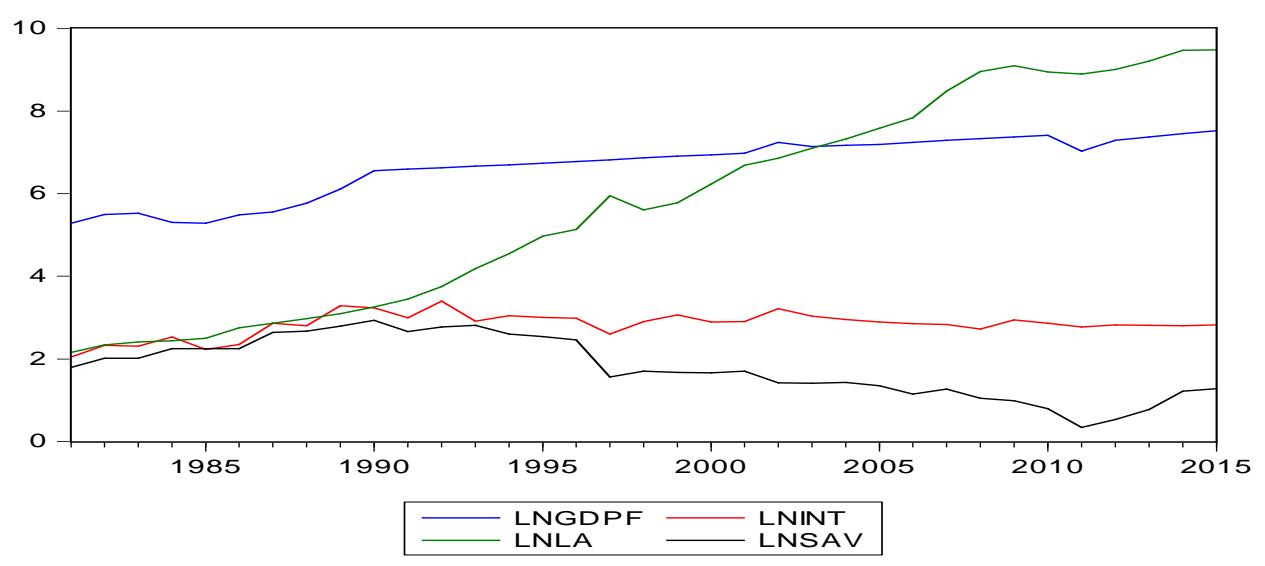

Fig 1: A Plot of the Economic Macro Variables

Figure 1 above shows the plot of the natural log transformed of the variables used in this study. There evidence of positive growth in the performance of the macro economic variables.

Table 1: Descriptive Statistics of the Economic Macro variables

\begin{tabular}{|c|c|c|c|c|}
\hline & LNGDPF & LNINT & LNLA & LNSAV \\
\hline Mean & 6.658313 & 2.828667 & 5.751817 & 1.793394 \\
\hline Median & 6.867640 & 2.867330 & 5.777030 & 1.702930 \\
\hline Maximum & 7.523930 & 3.394510 & 9.479310 & 2.933860 \\
\hline Minimum & 5.282750 & 2.047690 & 2.151760 & 0.343590 \\
\hline Std. Dev. & 0.729900 & 0.297896 & 2.564343 & 0.725453 \\
\hline Skewness & -0.806143 & -0.749199 & 0.051584 & -0.084856 \\
\hline Kurtosis & 2.229984 & 3.516531 & 1.527985 & 1.944436 \\
\hline Jarque-Bera & 4.655571 & 3.663336 & 3.175479 & 1.666900 \\
\hline Probability & 0.097511 & 0.160146 & 0.204387 & 0.434547 \\
\hline Sum & 233.0409 & 99.00334 & 201.3136 & 62.76879 \\
\hline Sum Sq. Dev. & 18.11361 & 3.017238 & 223.5791 & 17.89360 \\
\hline Observations & 35 & 35 & 35 & 35 \\
\hline
\end{tabular}

Key: LNGDDF- Natural Logarithm transform of GDP of Financial Institutions LNINT- Natural Logarithm transform of Lending Rates LNLA- Natural Logarithm transform of Loans and Advances LNSAV-Weighted Average Savings

Table 1 above shows the descriptive statistics of the macro economic variables. The economic macro variables are all normally distributed (since P-values $>0.05$ )

Table 2: ADF Test of the Economic Macro variables

\begin{tabular}{|l|l|l|l|l|l|}
\hline & \multicolumn{2}{|c|}{ Level } & \multicolumn{2}{c|}{$1^{\text {st }}$ Difference } & \\
\hline Variables & ADF Value & p-value & ADF Value & P-value & Order \\
\hline LNGDPF & -1.5884 & 0.4774 & -5.0987 & 0.0002 & $\mathrm{I}(1)$ \\
LNLA & -0.0937 & 0.9423 & -5.1918 & 0.0002 & $\mathrm{I}(1)$ \\
LNSAV & -0.8215 & 0.8001 & -5.4345 & 0.0001 & $\mathrm{I}(1)$ \\
\hline
\end{tabular}




\begin{tabular}{|l|l|l|l|l|l|}
\hline LNINT & -3.6566 & 0.0103 & -5.2552 & 0.0001 & $\mathrm{I}(0)$ \\
\hline
\end{tabular}

Table 2 above, The GDP, Loans and Advances, Average Savings are stationary in their first difference, that is integrated of order one I(1). While the Natural Logarithm transform of Lending Rates is stationary at level. This also shows the appropriateness of ARDL model since it can handle values at different order of integration (Udoh et al., 2015).

\section{Table 3: Standard ARDL(1,1,1,2) Model}

Dependent Variable: D(LNGDPF)

Method: Least Squares

Date: 06/13/18 Time: 13:28

Sample (adjusted): 19842015

Included observations: 32 after adjustments

\begin{tabular}{crrrr}
\hline \hline Variable & Coefficient & Std. Error & t-Statistic & Prob. \\
\hline \hline C & 1.469084 & 0.517229 & 2.840298 & 0.0105 \\
D(LNGDPF(-1)) & 0.071123 & 0.175800 & 0.404567 & 0.6903 \\
D(LNLA) & 0.160886 & 0.107135 & 1.501718 & 0.1496 \\
D(LNLA(-1)) & 0.131408 & 0.127163 & 1.033389 & 0.3144 \\
D(LNSAV) & 0.006272 & 0.119139 & 0.052645 & 0.9586 \\
D(LNSAV(-1)) & 0.041953 & 0.130089 & 0.322494 & 0.7506 \\
D(LNINT) & 0.366587 & 0.136772 & 2.680277 & 0.0148 \\
D(LNINT(-1)) & -0.377071 & 0.206280 & -1.827956 & 0.0833 \\
D(LNINT(-2)) & -0.217285 & 0.130128 & -1.669785 & 0.1114 \\
LNGDPF(-1) & -0.819942 & 0.175217 & -4.679576 & 0.0002 \\
LNLA(-1) & 0.173731 & 0.057879 & 3.001638 & 0.0073 \\
LNSAV(-1) & 0.008326 & 0.143103 & 0.058179 & 0.9542 \\
LNINT(-1) & 1.045864 & 0.255051 & 4.100603 & 0.0006 \\
\hline \hline R-squared & 0.680777 & Mean dependent var & 0.062426 \\
Adjusted R-squared & 0.479163 & S.D. dependent var & 0.145633 \\
S.E. of regression & 0.105102 & Akaike info criterion & -1.376563 \\
Sum squared resid & 0.209883 & Schwarz criterion & -0.781108 \\
Log likelihood & 35.02501 & Hannan-Quinn criter. & -1.179186 \\
F-statistic & 3.376628 & Durbin-Watson stat & 1.913919 \\
Prob(F-statistic) & 0.008852 & & \\
\hline \hline
\end{tabular}

\section{Table 4: Bound Testing}

Wald Test:

Equation: Untitled

\begin{tabular}{lccc}
\hline \hline Test Statistic & Value & df & Probability \\
\hline \hline F-statistic & 6.408593 & $(4,19)$ & 0.0019 \\
Chi-square & 25.63437 & 4 & 0.0000 \\
\hline \hline
\end{tabular}

Null Hypothesis: $C(10)=C(11)=C(12)=C(13)=0$

Null Hypothesis Summary:

\begin{tabular}{lll}
\hline \hline Normalized Restriction $(=0)$ & Value & Std. Err. \\
\hline \hline
\end{tabular}




\begin{tabular}{lll}
$\mathrm{C}(10)$ & -0.819942 & 0.175217 \\
$\mathrm{C}(11)$ & 0.173731 & 0.057879 \\
$\mathrm{C}(12)$ & 0.008326 & 0.143103 \\
$\mathrm{C}(13)$ & 1.045864 & 0.255051 \\
\hline \hline
\end{tabular}

Restrictions are linear in coefficients.

Table 3 above presents the Standard ARDL $(1,1,1,2)$, while table 4 presents the Bound testing for cointegration that is to ascertain the evidence of long run association among the macro economic variables. The Pesaran critical values: Lower bound=2.86 and Upper Bound $=4.01$ with F-calculated value $=6.408593>4.01$. It means that the macro economic variables have long run relationships

Table 5: Short Run and ecm coefficient of ARDL(1,1,1,2) Model Dependent Variable: D(LNGDPF) Method: Least Squares

Date: 06/13/18 Time: 13:34

Sample (adjusted): 19842015

Included observations: 32 after adjustments

\begin{tabular}{crrrr}
\hline \hline Variable & Coefficient & Std. Error & t-Statistic & Prob. \\
\hline \hline C & -0.034124 & 0.043973 & -0.776022 & 0.4460 \\
D(LNGDPF(-1)) & 0.173986 & 0.198117 & 0.878197 & 0.3893 \\
D(LNLA) & 0.255263 & 0.119745 & 2.131729 & 0.0444 \\
D(LNLA(-1)) & 0.101409 & 0.118428 & 0.856290 & 0.4011 \\
D(LNSAV) & 0.047274 & 0.107131 & 0.441270 & 0.6633 \\
D(LNSAV(-1)) & -0.089707 & 0.121263 & -0.739771 & 0.4673 \\
D(LNINT) & 0.240741 & 0.139547 & 1.725157 & 0.0985 \\
D(LNINT(-1)) & -0.015937 & 0.188414 & -0.084587 & 0.9334 \\
D(LNINT(-2)) & -0.054164 & 0.128498 & -0.421516 & 0.6775 \\
ECM(-1) & -0.615602 & 0.190418 & -3.232903 & 0.0038 \\
\hline \hline R-squared & 0.491612 & Mean dependent var & 0.062426 \\
Adjusted R-squared & 0.283635 & S.D. dependent var & 0.145633 \\
S.E. of regression & 0.123262 & Akaike info criterion & -1.098707 \\
Sum squared resid & 0.334256 & Schwarz criterion & -0.640665 \\
Log likelihood & 27.57931 & Hannan-Quinn criter. & -0.946879 \\
F-statistic & 2.363778 & Durbin-Watson stat & 1.878239 \\
Prob(F-statistic) & 0.048206 & & & \\
\hline \hline
\end{tabular}

From table 5 above, the short run coefficients and the Error Correction coefficient (ECM) are presented. The Error Correction coefficient (ECM) is negative with estimate as -0.615602 with a p-value of 0.0038 which is very significant. This implies a reasonable high speed of equilibrium after a shock (that is $61.6 \%$ ). Approximately $62 \%$ of disequilibria from the previous year's shock converge back to the long - run equilibrium in the current year. The expected sign of ECM coefficient is in line with the work of Okafor and Shuaibu, (2016). 
Table 6: Multicollinearity test

Variance Inflation Factors

Date: 06/13/18 Time: 13:37

Sample: 19812015

Included observations: 32

\begin{tabular}{cccc}
\hline \hline Variable & $\begin{array}{c}\text { Coefficient } \\
\text { Variance }\end{array}$ & $\begin{array}{c}\text { Uncentered } \\
\text { VIF }\end{array}$ & $\begin{array}{c}\text { Centered } \\
\text { VIF }\end{array}$ \\
\hline \hline C & 0.001934 & 4.072471 & NA \\
D(LNGDPF(-1)) & 0.039250 & 2.010504 & 1.700190 \\
D(LNLA) & 0.014339 & 2.926163 & 1.451016 \\
D(LNLA(-1)) & 0.014025 & 2.867119 & 1.399789 \\
D(LNSAV) & 0.011477 & 1.455724 & 1.442813 \\
D(LNSAV(-1)) & 0.014705 & 1.861925 & 1.842712 \\
D(LNINT) & 0.019473 & 2.101215 & 2.090311 \\
D(LNINT(-1)) & 0.035500 & 3.831176 & 3.814415 \\
D(LNINT(-2)) & 0.016512 & 1.866795 & 1.846716 \\
ECM(-1) & 0.036259 & 2.253638 & 2.251382 \\
\hline \hline
\end{tabular}

There is no presence of Multicollinearity $(\mathrm{VIF}<10)$

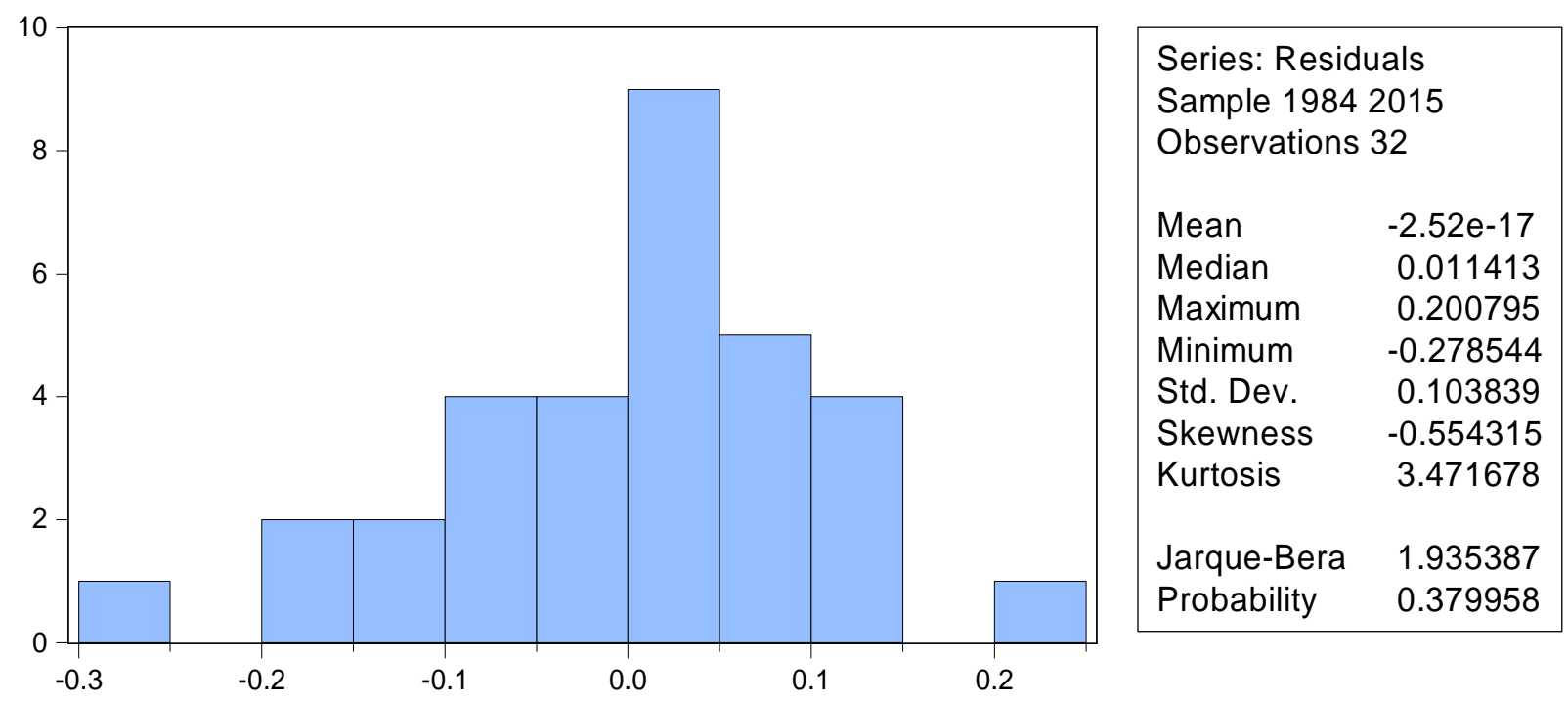

Fig 2: Normality Test of the Residuals

Table 7: Breusch-Godfrey Serial Correlation LM Test:

\begin{tabular}{llll}
\hline \hline F-statistic & 0.676693 & Prob. F(2,20) & 0.5196 \\
Obs*R-squared & 2.028173 & Prob. Chi-Square(2) & 0.3627 \\
\hline
\end{tabular}

Table 8: Heteroskedasticity Test: Breusch-Pagan-Godfrey

\begin{tabular}{llll}
\hline \hline F-statistic & 1.349094 & Prob. F(9,22) & 0.2693 \\
Obs*R-squared & 11.38014 & Prob. Chi-Square(9) & 0.2505 \\
Scaled explained SS & 6.647447 & Prob. Chi-Square(9) & 0.6738 \\
\hline \hline
\end{tabular}


The Diagnostic test of the estimated short run ARDL $(1,1,1,2)$ obtained is free from the problem of multicollinearity (see Table 6), no presence of serial correlation (see Table 7) and no presence of Heteroskedasticity (Table 8) while the residual is normally distributed (see Figure 2). This means that the estimated model is robust (Okafor and Shuaibu, 2016)

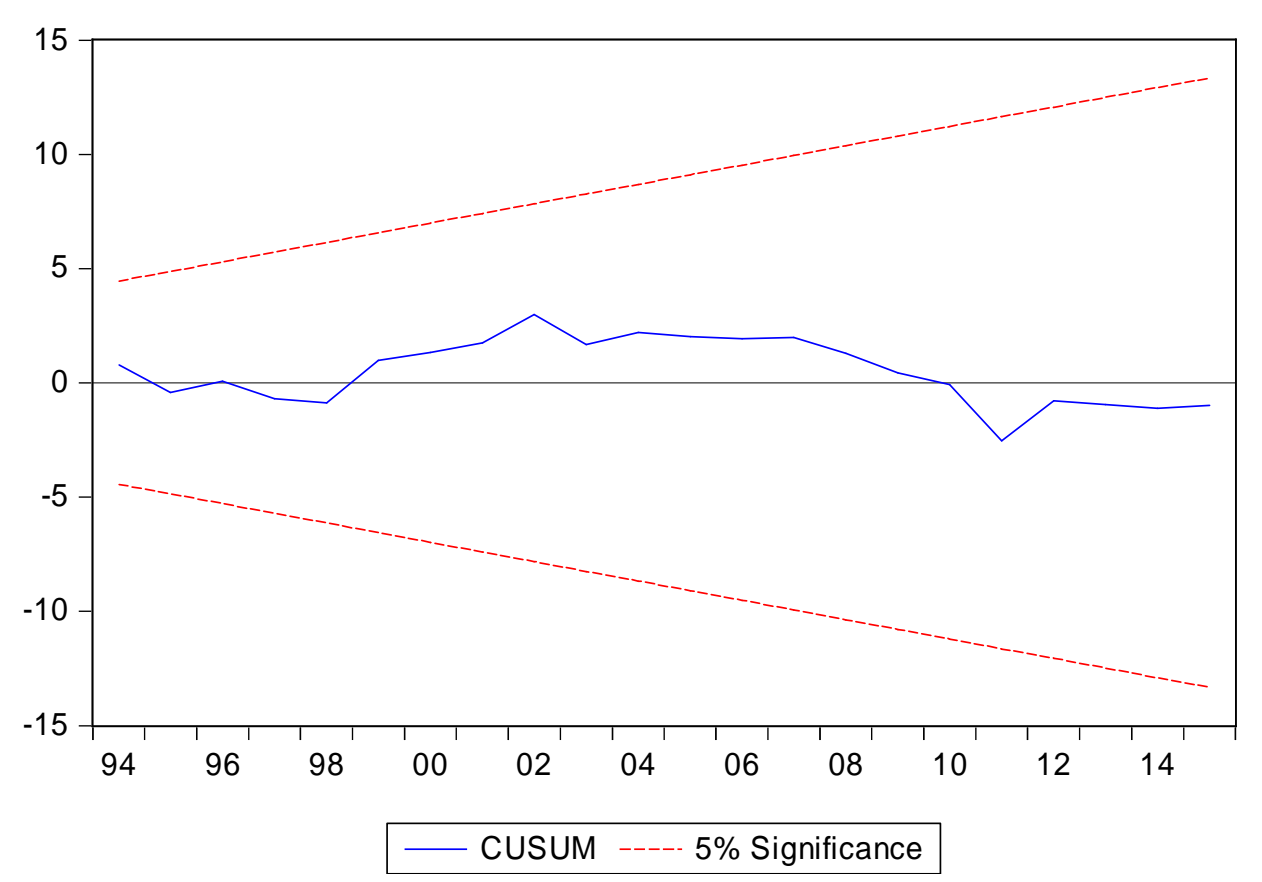

Fig. 3: CUSUM Stability Test

Figure 3 above shows the CUSUM stability test, the test shows the stability of the model. This supports the results from the diagnostic and the residual analyses of the estimated ARDL model.

Table 9: Long Run Coefficients

Dependent variable: LNGDPF

\begin{tabular}{|l|c|l|l|l|l|}
\hline Variables & Coefficients & Standard error & t-value & p-value & Remarks \\
\hline LNLA & 0.211882 & 0.053426 & 3.965925 & 0.0008 & Significant \\
LNSAV & 0.010154 & 0.174564 & 0.058167 & 0.9542 & Not Significant \\
LNINT & 1.275534 & 0.220018 & 5.797397 & 0.0000 & Significant \\
\hline
\end{tabular}

It results in the table 9 above present the long run relationship between GDP and, loans and advances, savings and interest rate. The Natural Logarithm transform of Loans and Advances 
and Natural Logarithm transform of Lending Rate have a long run positive significant relationship with Natural Logarithm transform of GDP of Financial Institutions while Natural transform of Savings have a long run positive non-significant relationship with Natural Logarithm transform of GDP of Financial Institutions. This confirms the poor saving culture of the Nigeria people (Nwachukwu and Odigie 2011).

\subsection{Conclusion and Recommendation}

This study applied the ARDL model to examine the contributions of commercial Banks to GDP growth in Nigeria. To achieve this, annual data covering 1981 to 2015 for loans and advances, savings, lending rates and GDP of Financial Institutions were collected from CBN bulletin. The ADF test revealed that the variables are $\mathrm{I}(1)$ except for lending rate which was of $\mathrm{I}(0)$ order. The ARDL(1,1,1,2) model revealed that loans and advances, and lending rates are significantly positively related to GDP in Nigeria but savings was not significant in the model, this is in line with work of (Nwachukwu and Odigie 2011).

The model revealed some evidence of short run relationships while the ecm(-1) was -0.6156 (Pvalue $=0.0038<0.05$ ) which means that the rate of the speed of adjustment to equilibrium is $61.56 \%$ annually. The estimated model is free from serial correlation, multicollinearity, heteroscedasticity while the model is stable and the residuals are normally distributed. The study recommends that savings and savings culture should be encouraged in Nigeria since economic theory states that savings and investment are related in any economic development.

\section{References}

Abubakar, A., \& Gani, I. M. (2013). Impact of banking sector development on economic growth: Another Look at the Evidence from Nigeria. Journal of Business Management \& Social Sciences Research(JBM\&SSR), 2(4):47-57.

Adekunle, O. A., Salam, G. O., \& Adedipe, O. A. (2013). Impact of financial sector development on the Nigerian economic growth. American Journal of Business and Management, 2(4), 347- 356.

Azege, M. (2007).The impact of financial intermediation on economic growth: The Nigerian perspective. Research Paper, Department of Economics, Lagos State University. 
Bhusal, B. P. (2012). Impact of financial policy reforms on financial development and Economic growth in Nepal. International Journal of Business and Social Science, 3(14), $33-45$.

Bigstein, A., \& Soderbom, M. (2005) Credit constraints in manufacturing enterprises in Africa. The Centre for the study of African Economies Working Paper Series, Oxford University Press.

Doguwa, S. I. and Alade, S. O.(2015). On Time Series Modeling of Nigeria's External Reserves. CBN Journal of Applied Statistics, 6(1a):1-28.

Hashim, Y. A. (2012). Impact of financial intermediation on the growth of real sector of the Nigerian economy. The post graduate school, Ahmadu Bello University,Zaria.

Johanson, S. and Juselius, K. (1990). Maximum Likelihood Estimation and inference on cointegration with applications to Demands for money. Oxford bulletin of Economics and Statistics 52, $169-210$.

Musa, Y. and Gulumbe, S. U.(2014). Analyzing Nigeria Inflation and Government Revenues Using ARDL Approach. Nigerian Statistical Association 2014 Annual Conference Proceedings : 195-209

Nwachukwu, T.E \& Odigie, P. (2011): What Drives Private Savings in Nigeria. AERC Research paper 212. African Economic Research Consortium, Nairobi.

Okafor C, \& Shaibu I (2016): Modelling Economic Growth Functions in Nigeria: An ARDL Approach. Asian Journal of Economic and Emperical Research, 3(1): 84 - 93.

Pandey, I. M. (2006). Financial management: Credit policy. ( $9^{\text {th }}$ Edition). New Delhi: Vikas Publishing House PVT LTD.

Pearce, D.W. (1992). Dictionary of modern economics. ( $1^{\text {st }}$ Edition). London: Macmillan Press.

Pesaran, M. H., Shin, Y. and Smith, R. J.(2001). Bound Testing Approaches to the Analysis of Level Relationship. Journal of Applied Economics, 16:289-326.

Shittu, O. I. and Yaya, O. S.(2011). On Fractionally Integrated Logistic Smooth Transitions in Time Series. CBN Journal of Applied Statistics, 2(1):1-13.

Udoh, E., Afangideh, U. and Udeaja, E. A. .(2015). Fiscal Decentralization, Economic Growthand Human Resources Development in Nigeria: Autoregressive Distributed Lag (ARDL) Approach. CBN Journal of Applied Statistics, 6(1a):69-93.

Udom, S. I. and Yaaba, B. N.(2015). Determining the Optimal Monetary policy Instrument for Nigeria. CBN Journal of Applied Statistics, 6(1a):29-47. 